\title{
KONSEP LITERASI DALAM TELAAH SIBI 2016: SEBUAH KAJIAN INTERTEKS TAHAP AWAL
}

\author{
Resti Nurfaidah \\ Balai Bahasa Jawa Barat \\ sineneng1973@gmail.com
}

\begin{abstract}
Abstrak
SIBI 2016 merupakan ajang pertukaran pikiran para peneliti dan peminat bahasa ibu, berikut sastra dan budaya lokal yang diselenggarakan pada setiap dua tahun oleh Balai Bahasa Jawa Barat. 49 pemakalah pada kajian sastra dari sekitar 200-an pemakalah secara keseluruhan, turut meramaikan perhelatan ilmiah tersebut. Dari pengamatan pada buku kumpulan makalah tersebut, sebagian besar mengangkat tema tentang peran dan kaitan sastra dengan konsep literasi. Makalah ini ditulis berdasarkan pada hasil pengamatan terhadap makalah-makalah sastra tersebut. Pengamatan tersebut dilakukan dengan pendekatan konsep analisis wacana kritis. Metode penelitian yang dilakukan adalah analisis deskriptif komparatif, yaitu menjabarkan setiap poin penting dalam korpus penelitian dan pandangan penulisnya terhadap isu dalam dunia sastra dengan konsep literasi. Data yang diperoleh lalu dibandingkan dan dituangkan ke dalam bentuk sebuah makalah. Hipotesis yang diperoleh dari pengamatan tersebut, antara lain, sastra - terutama sastra lokalmemiliki peranan yang sangat penting dalam pengembangan program literasi, banyaknya kearifan lokal yang perlu diketahui dan dihayati oleh generasi muda agar mengenali budaya lokal serta jati diri, pelestarian sastra lokal dalam program literasi perlu mendapatkan dukungan dari berbagai pihak yang terlibat dalam program tersebut, serta memperluas wawasan terhadap isu dalam penelitian sastra dan budaya. Kata Kunci: sastra, sastra lokal, literasi, kearifan lokal.
\end{abstract}

\begin{abstract}
SIBI 2016 was being an arena of thoughts of mother tongue-following with its local cultures and literatures-researchers and enthusiasts. It was held in every two years by Balai Bahasa Jawa Barat. 49 researchers of literature-part of those 200-an ones who presented their papers, enlivened the scientific arena. From proceeding observations, most researchers presented the themes of literatures role and relation to the concept of literacy. This article was written based on the observation to those literary articles that enclosed the concept of literacy. Discourse analysis was used as the approach with descriptive comparative analysis as a method: by describing points of those corpus and the view of the authors of the articles to the latest issues of literature connecting to the concept of the literacy itself. Data were then were then compared and--as the final step--was composing an article. Hypothesis were below: literature-especially the local ones, had a very important
\end{abstract}


role in the development of literacy; many local wisdom that should be known and be preserved amongst young generations, so they could recognized their own local culture and identity; preservation of local literature in the literacy program needs the support of the various parts who being involved in the program; besides knowing the current issues in the literarature and culture.

Key Word: literature, local literature, literacy, local wisdom.

\section{Pendahuluan}

Seminar Internasional Bahasa Ibu (SIBI) 2016 merupakan sarana untuk bertukar pikiran dan wawasan tentang bahasa ibu dengan berikut kompleksitasnya yang diselenggarakan oleh Balai Bahasa Jawa Barat. Kegiatan dua tahunan tersebut juga dapat dikatakan sebagai arena pertemuan para peneliti serta peminat bahasa ibu. Satu hal yang menarik dalam kegiatan tersebut adalah kegiatan reuni antarpemakalah karena SIBI telah memiliki pelanggan setia yang senantiasa hadir dalam perhelatan tersebut. Tema yang diusung dalam SIBI 2016 adalah "Bahasa Ibu sebagai Sumber Budaya Literasi”. Makalah yang ditulis dan terkumpul dalam sebuah bunga rampai pada uamumnya mengangkat tema tentang sastra yang dihubungkan dengan kegiatan literasi. Gerakan literasi digalakkan pada tahun 2012-an sebagai upaya pemerintah untuk mengatasi persoalan rendahnya tingkat keterbacaan di negeri ini. Globalisasi juga ditengarai sebagai sumber perubahan radikal pada pandangan warga bumi pertiwi terhadap eksistensi kearifan lokal. Oleh karena itu, kebanyakan penulis yang turut berpartisipasi di dalam seminar tersebut mengangkat sastra dan budaya lokal sebagai basis pemerkaya program literasi.

Makalah ini ditulis sebagai rekapitulasi hasil pengamatan pada 20 makalah yang terdapat di dalam bunga rampai. Dari pengamatan tersebut dapat kita tarik benang merah situasi dan kondisi dunia literasi pada beragam wilayah di seluruh Indonesia saat itu. Sastra atau budaya lokal apa saja yang dianggap layak sebagai sumber pembelajaran. Metode pengamatan yang saya lakukan adalah analisis deskriptif komparatif dengan pendekatan strukturalisme secara umum pada setiap teks. Teks berupa makalah dipecah menjadi tiga kolom penting dari enam kolom pembahasan (lihat pada bagian lampiran). Tiga kolom pertama merupakan biodata karya dan penulis, serta halaman yang memuat makalah tersebut. Tiga kolom kanan 
merupakan hasil temusn berupa fokus penelitian, alasan atas tema yang diangkat, serta poin penting yang dapat berupa solusi terhadap masalah yang dihadapi dalam dunia literasi dan kearifan lokal, inti tentang kearifan lokal, atau saran untuk pihak-pihak yang terlibat itu.

\section{Hasil dan Pembahasan}

Dari keduapuluh makalah yang dikaji, 13 diantaranya (65\%) persen merupakan makalah yang ditulis berdasarkan pada kekhawatiran para peneliti terhadap fenomena literasi berbasis sastra dan budaya lokal yang mengalami pengabaian atau bahkan hampir punah. Ada pula peneliti yang menunjukkan kekhawatiran pada kegagalan aplikasi literasi dalam wujud lain, yaitu atensi terhadap kerusakan alam yang tertuang di dalam sebuah novel. Novel tersebut lalu dibedah dengan menggunakan konsep ekokritik. Ketigabelas makalah tersebut adalah (1) "Patu Mbojo Masyarakat Bima Sebagai Sumber Literasi dalam Bahasa Indonesia di Sekolah Dasar" (Nurul Uyun); (2) "Sastra Anak Sebagai Sarana Peningkatan Budaya Literasi” (Dessy Wahyuni); (3) "Kitab Tarojumah Kyai Rifa'i Literasi Ajaran Islam di Jawa" (Khristianto dan Widya Nirmalawati); (4) "Pelestarian Bahasa Betawi Melalui Lenong Betawi: Ancangan Peningkatan Budaya Literasi” (Riza Sukma); (5) "Peran Bahasa Ibu dalam Pengembangan Budaya Literasi: Revitalisasi Nadhoman di Perbatasan" (Elis Suryani Nani Sumarlina, Taufik Ampera, Asep Yusuf Hudayat, dan Mamat Ruhimat); (6) "Cerita Nyi Murtasiya dalam Seni Macapat di Kabupaten Cirebon: Kajian Struktur Teks, Konteks, fungsi, dan Nilai, serta Pemanfaatannya sebagai Bahan Pembelajaran di Sekolah" (Lailatul Munawaroh); (7) "Peran Sastra dalam Budaya Literasi" (Ninawati Syahrul); (8) "Sastra Lisan Cigawiran Berbasis Tradisi dan Religi (Asep Supriadi)"; (9) "Latar Belakang Budaya, Ungkapan, dan Alur Dongeng sebagai Bahan Pembelajaran Bahasa dan Sastra Indonesia di SD (Abdul Azis dan Irna Fitriana)"; (10) "Pembelajaran Aspek Lingkungan Penyair Puisi Melalui Pemanfaatan Strategi Two Stay Two Stray (TS-TS) (Andi Fatimah Yunus dan Aswati Asri)"; (11) "Menyimak Unsur, Alur, Tokoh, dan Perawatan Cerpen Melalui 
Penerapan Model Moody" (Hajrah dan Suarni Syam Saguni); (12) "Ekologi Sastra dalam Cerpen "Kanuku Leon” Karya Christian Dicky Sandi; dan (13) "Buku Bacaan Rusdi jeung Misnem: Pendidikan Literer Masa Kolonial dalam Geliat Modernitas" (Asep Yusuf Hudayat).

Pada umumnya, ketigabelas makalah tadi ditulis berlandaskan pada serangkaian kekhawatiran tentang kepunahan, pengabaian, atau tersingkirnya kearifan lokal, yaitu pada makalah nomor (1), (3), (4), (6), dan (8). Pada beberapa makalah tersebut ada pula yang mengangkat keprihatinan terhadap sistem pembelajaran sastra yang monoton, verbalistis, dan tidak mampu menyentuh sisi kebutuhan siswa untuk menyelami kearifan lokal dan akar budayanya, yaitu pada makalah nomor (9) dan (10). Sementara itu, penyampaian literasi secara tidak langsung, disampaikan melalui penelaahan langsung pada karya sastra, terdapat pada makalah nomor (5), (11), dan (12). Dua makalah berkaitan dengan kebijakan, yaitu makalah nomor (2) dan (7). Serangkaian kekhawatiran terjadi sebagai akibat dari bergesernya pandangan masyarakat pada kearifan lokal itu sendiri ketika datang pengaruh yang baru. Generasi muda cenderung untuk mengabaikan dan tidak menggunakan bahasa ibunya sendiri dan lebih memilih untuk menggunakan bahasa Indonesia atau bahasa asing. Warisan kearifan lokal kebanyakan merupakan generasi tua. Tidak sedikit di antara mereka mengalami kesulitan untuk mencari pewarisnya. Dari ketigabelas makalah tadi, dua di antaranya menunjukkan bahwa sejak zaman kolonial dulu, literasi sudah digalakkan, baik oleh pribumi maupun penjajah. Ada pula yang bergabung dan bekerja sama untuk menulis sebuah karya seperti pada bahasan dalam novel nomor 13. Hudayat menyampaikan bahwa Literasi bukan merupakan barang yang baru dengan contoh karya sastra yang dibahas adalah Rusjdi jeung Miskam (A. C. Deenik dan R. Djajadiredja). Namun, dalam kondisi terjajah, sastra dijadikan sebagai media penitipan doktrin kolonialisme, dan feodalisme. Pribumi dijejali dengan pemikiran baru dan mengubah keyakinannya pada nilai-nilai kearifan lokal seolah-olah sebagai penghalang terhadap kemajuan zaman. Pribumi dijejali dengan konsep medernitas yang dianggap lebih mampu meninggikan kedudukan seseorang. Sudah sejak lama pula Indonesia memiliki pegiat literasi. Mungkin warga 
Indonesia lebih mengenal R.A. Kartini dan Dewi Sartika, Ki Hajar Dewantara, atau Rohana Kudus. Namun, jarang sekali orang menyebut nama Kyai Rifa'I. Padahal dari karya tulisnya yang brilian termuat ajakan untuk mengobarkan semangat juang untuk melawan penjajah. Karya sastra Kyai Rifa'I dapat dikatakan sebagai sastra kanon. Pemilihan diksinya luar biasa sehingga agar tidak dimengerti kedalaman artinya oleh orang awam. Hal serupa terjadi pula di kalangan santri-santri pesantren di kawasan Desa Cigawir yang memiliki tradisi tembang Cigawiran. Tradisi Cigawiran merupakan tradisi lokal yang diturunkan bukan pada keturunan langsung, melainkan kepada para santri yang kelak akan meneruskan jejak langkah sang pemilik pesantren. Tradisi Cigawiran, seharusnya mendapatkan upaya pelestarian karena hanya orangorang yang berada di desa setempat yang dapat menikmatinya.

Sementara itu, tujuh makalah lain ditulis berdasarkan pada keragaman latar. "Peranan Akhbar Melayu di Malaysia dalam Budaya Literasi Sastera (Nadiatul Shakinah binti Abdul Rahman" (Salmah Jan binti Noor Muhammad, dan Arba'ie bin Sujud) dan "Rubrik Si Palui dalam Geliat Budaya Literasi di Kalimantan Selatan" (Musdalipah) merupakan makalah yang mengangkat tema sanjungan atau pujian kepada media cetak yang mampu menjadi sarana untuk menampung dan menyanpaikannya kepada rakyat Indonesia. media tersebut memiliki lahan untuk penulisan artikel bertemakan sastra... "Ungkapan Adat dan Budaya Literasi “(Nazurty Suhaimi); "Literasi Religiusitas dalam Struktur Mantra Panangka Hujan di Sumatera Barat" (Yenni Hayati dan Melisa Anggraini); dan "Peran Bahasa Ibu dalam Pengembangan Budaya Literasi: Keterjalinan Struktur dan Makna Teks Mantra Pertanian" (Elis Suryani Nani Sumarlina, Undang Ahmad Darsa, dan Indira Lanti K.) sama-sama mengangkat tema mantra. Mantra akan sulit dipahami jika ditelusuri dengan struktur fisiknya. Ungkapan adat berperanan penting dalam penunjukkan seorang kepala adat. Sementara itu, penangka hujan dibacakan pada saat ritual mengusir hujan. Mantra hanya dapat dibacakan setelah aspek audionya dinyalakan, yaitu dibacakan oleh perapalnya atau pawang. Ada kalanya pawang tidak membaca mantra tersebut dengan lantang, tetapi berbisik lirih nyaris tidak terdengar. Sementara 
itu, makalah berjudul "Riak Sajak Sebagai Riak Literasi Warga Purwakarta" (Nia Kurnia) menggambarkan besarnya perhatian dan dukungan instansi terkait terhadap perkembangan sastra. Makalah berjudul "Si Kabayan: dari Kelisanan Hingga Keliterasian" (Yeni Mulyani Supriatin) lebih bertitik tolak pada aspek Si Kabayan sebagai imej legendaris di Tatar Parahyangan.

Inti dari pembahasan dalam keduapuluh makalah itu adalah literasi hanya dapat berjalan lancar jika mendapat campur tangan dari berbagai pihak, termasuk penguasa, penerbit, atau pegiat literasi. Kesadaran berliterasi terutama harus dipupuk dari diri sendiri. warga negeri ini harus memupuk mental untuk maju dan berpendidikan. Literasi bukan sekadar urusan membaca dan menulis, Berdasarkan Deklarasi Praha Tahun 2013, literasi berkaitan dengan kemampuan manusia untuk berkomunikasi dengan sesamanya. Untuk dapat berkomunikasi dengan sesama, ia harus memiliki bekal yang cukup, yaitu pengertian, pemahaman, etika, moral, dan sebagainya. Literasi menjadi sangat luas bahkan merambah ke berbagai ranah kehidupan, seperti teknologi, ekonomi, media, atau informasi. Literasi bukan perkara mudah karena ia berkaitan dengan beragam bentuk kecakapan yang berbenturan dengan beragam karakter manusia dengan keragaman latar belakang budayanya. Sekali lagi Literasi bukan hal yang mudah, tetapi ia akan menjadi mudah jika didukung dengan baik oleh pihak-pihak yang peduli literasi seutuhnya.

\section{Simpulan}

SIBI Tahun 2016 mengangkat tema Bahasa Ibu Sebagai Sumber Budaya Literasi. Sekitar 200-an pemakalah, sebagian di antaranya merupakan pelanggan tetap, turut berpartisipasi dalam menyuarakan hasil penelitiannya. 20 dari 40 makalah sastra secara keseluruhan dipilih sebagai sampel untuk tahapan pengamatan. Dari hasil pengamatan tersebut, kebanyakan menyuarakan dukungan yang positif terhadap budaya literasi yang kini sedang giat-giatnya digalakkan oleh pemerintah. Budaya literasi juga dikaitkan dengan kearifan lokal yang dianggap sebagai jalan untuk mengetahui akar budaya dasar seorang warga Indonesia. Budaya literasi bukan merupakan barang baru, melainkan sudah ada sejak masa lalu. Pada zaman kolonial, 
literasi menjadi sarana untuk menyebarkan doktrin modernitas dan memengaruhi khalayak pada saat itu bahwa adat itu tidak benar, adat itu hanya membuat repot seseorang. Pengaruh dari barat dianggap sebagai budaya baru yang lebih bergengsi. Tidak heran jika pengaruh tersebut tertanam demikian kuat sehingga generasi muda sekarang lebih bersikap pro terhadap modernitas itu serta cenderung meninggalkan budaya leluhurnya. Hal itu sudah dapat kita lihat pada beberapa pengguna dan anggota beberapa etnis di wilayah negeri ini. Berdasarkan pada kekhawatiran, para penulis makalah sepakat bahwa kearifan lokal tetap harus dijaga dan dilestarikan sebagai sumber pendidikan moral, baik di ranah domestik maupun di ranah publik, kearifan lokal tersebut berperanan sangat penting sebagai penumbuh akar budaya di negeri ini. Budaya literasi sangat penting bagi pembentukan manusia yang berkarakter. Namun, untuk mencapai tujuan tersebut, budaya literasi harus dilakukan dan didukung oleh berbagai pihak yang berkaitan dengan hal itu. Membaca serangkaian makalah dalam bunga rampai SIBI Tahun 2016 tersebut ibarat menyelam di lautan wawasan yang luas dengan banyaknya tema-tema menarik yang dipresentasikan.

\section{Daftar Referensi}

Uyun, Nurul. 2016. "Patu Mbojo Masyarakat Bima Sebagai Sumber Literasi dalam Bahasa Indonesia di Sekolah Dasar" dalam Bunga Rampai: Bahasa Ibu sebagai Sumber Budaya Literasi, halaman 67--68. Jatinangor: Unpad Press.

Wahyuni, Dessy. 2016. "Sastra Anak Sebagai Sarana Peningkatan Budaya Literasi" dalam Bunga Rampai: Bahasa Ibu sebagai Sumber Budaya Literasi, halaman 69--77. Jatinangor: Unpad Press.

Rahman, Nadiatul Shakinah binti Abdul, Noor Muhammad, Salmah Jan binti, dan Sujud. 2016 "Peranan Akhbar Melayu di Malaysia dalam Budaya Literasi Sastera" dalam Bunga Rampai: Bahasa Ibu sebagai Sumber Budaya Literasi, halaman 69--77. Jatinangor: Unpad Press.

Khristianto dan Nirmalawati Widya. 2016. "Kitab Tarojumah Kyai Rifa'i Literasi Ajaran Islam di Jawa" dalam Bunga Rampai: Bahasa Ibu sebagai Sumber Budaya Literasi, halaman 69--77. Jatinangor: Unpad Press. 
Musdalipah. 2016. "Rubrik Si Palui dalam Geliat Budaya Literasi di Kalimantan Selatan” dalam Bunga Rampai: Bahasa Ibu sebagai Sumber Budaya Literasi, halaman 97--101. Jatinangor: Unpad Press.

Nazurty Suhaimi. 2016. "Ungkapan Adat dan Budaya Literasi" dalam Bunga

Rampai: Bahasa Ibu sebagai Sumber Budaya Literasi, halaman 103--109. Jatinangor: Unpad Press.

Hayati, Yenni, dan Melisa Anggraini 2016. "Literasi Religiusitas dalam Struktur Mantra Panangka Hujan di Sumatera Barat” dalam Bunga Rampai: Bahasa Ibu sebagai Sumber Budaya Literasi, halaman 111--119. Jatinangor: Unpad Press.

Sumarlina, Elis Suryani Nani, Darsa, Undang Ahmad, dan Lanti K., Indira. 2016. "Peran Bahasa Ibu dalam Pengembangan Budaya Literasi: Keterjalinan Struktur dan Makna Teks Mantra Pertanian” dalam Bunga Rampai: Bahasa Ibu sebagai Sumber Budaya Literasi, halaman 121--128. Jatinangor: Unpad Press.

Asep Yusuf Hudayat. 2016. "Buku Bacaan Rusdi jeung Misnem: Pendidikan Literer Masa Kolonial dalam Geliat Modernitas”dalam Bunga Rampai: Bahasa Ibu sebagai Sumber Budaya Literasi, halaman 129--135. Jatinangor: Unpad Press.

Sukma, Riza. 2016. "Pelestarian Bahasa Betawi Melalui Lenong Betawi: Ancangan Peningkatan Budaya Literasi” dalam Bunga Rampai: Bahasa Ibu sebagai Sumber Budaya Literasi, halaman 137--144. Jatinangor: Unpad Press.

Sumarlina, Elis Suryani Nani, Ampera, Taufik, Hudayat, Asep Yusuf, dan Ruhimat, Mamat. 2016. "Peran Bahasa Ibu dalam Pengembangan Budaya Literasi: Reivtalisasi Nadhoman di Perbatasan” dalam Bunga Rampai: Bahasa Ibu sebagai Sumber Budaya Literasi, halaman 145--152. Jatinangor: Unpad Press.

Kurnia, Nia. 2016. "Riak Sajak Sebagai Riak Literasi WArga Purwakarta” dalam Bunga Rampai: Bahasa Ibu sebagai Sumber Budaya Literasi, halaman 153-159. Jatinangor: Unpad Press. 
Munawaroh, Lailatul. 2016. "Cerita Nyi Murtasiya dalam Seni Macapat di Kabupaten Cirebon (Kajian Struktur Teks, Konteks, fungsi, dan Nilai, serta Pemanfaatannya sebagai Bahan Pembelajaran di Sekolah)" dalam Bunga Rampai: Bahasa Ibu sebagai Sumber Budaya Literasi, halaman 161--170. Jatinangor: Unpad Press.

Supriatin, Yeni Mulyani. 2016. "Si kabayan: dari Kelisanan Hingga Keliterasian" dalam Bunga Rampai: Bahasa Ibu sebagai Sumber Budaya Literasi, halaman 171--179. Jatinangor: Unpad Press.

Syahrul, Ninawati 2016. "Peran Sastra dalam Budaya Literasi” dalam Bunga Rampai: Bahasa Ibu sebagai Sumber Budaya Literasi, halaman 181--190. Jatinangor: Unpad Press.

Supriadi, Asep. 2016. "Sastra Lisan Cigawiran Berbasis Tradisi dan Religi" dalam Bunga Rampai: Bahasa Ibu sebagai Sumber Budaya Literasi, halaman 191-197. Jatinangor: Unpad Press.

Azis, Abdul, dan Fitriana, Irna. 2016. "Latar Belakang Budaya, Ungkapan, dan Alur Dongeng sebagai Bahan Pembelajaran Bahasa dan Sastra Indonesia di SD" dalam Bunga Rampai: Bahasa Ibu sebagai Sumber Budaya Literasi, halaman 199-205. Jatinangor: Unpad Press.

Yunus, Andi Fatimah, dan Asri, Aswati. 2016. "Pembelajaran Aspek LIngkungan Penyair Puisi Melalui Pemanfaatan Strategi Two Stay Two Stray (TS-TS)" dalam Bunga Rampai: Bahasa Ibu sebagai Sumber Budaya Literasi, halaman 207--214. Jatinangor: Unpad Press.

Hajrah, dan Saguni, Suarni Syam. 2016. "Menyimak Unsur, Alur, Tokoh, dan Perawatan Cerpen Melalui Penerapan Model Moody" dalam Bunga Rampai: Bahasa Ibu sebagai Sumber Budaya Literasi, halaman 215--222. Jatinangor: Unpad Press.

Larasati, Maria Marietta Bali. 2016. "Ekologi Sastra dalam Cerpen "Kanuku Leon" Karya Christian Dicky Sandi” dalam Bunga Rampai: Bahasa Ibu sebagai Sumber Budaya Literasi, halaman 223--234. Jatinangor: Unpad Press. 